\section{Chemical Engineering}

By J. M. Coulson and J. F. Richardson. Vol. 2 : Unit Operations. Pp. xvi $+387-975+65$ plates. (London: Pergamon Press, Ltd., 1955.) 60s. net.

$7 \mathrm{HE}$ second volume of "Chemical Engineering" completes the treatment of unit operations of which the more fundamental fluid flow and mass transfer were the main theme of Vol. 1 (Nature, 175, 228 (1955)). Flow of fluids past particles includes filtration, sedimentation, and gas cleaning ; mass transfor across an interface includes distillation, absorption, liquid-liquid extraction and leaching. Finally we have evaporation, crystallization, drying, size reduction of solids and mixing. Physical reactions only are considered owing to a paucity of rigorous methods of solution where chemical reactions are involved; similarly such subjects as automatic control and the design of reactors have been specifically excluded.

As with the first volume, each chapter contains a list of the more important references and a list of symbols and is very well illustrated with line diagrams, sectional drawings and photographs of equipment used in chemical engineering operations. An appendix contains 121 problems of university degree standard.

The more fundamental treatment in Vol. $\mathbf{1}$ is utilized as required in the second volume, as in the application of mass transfer in Chapter 7 to absorption in Chapter 19. The treatment throughout is mathematical with a slight tendency to underplay the physical conditions underlying the various operations. Thus, in so far as bubbles and drops are concerned, whereas Stokes's law is thoroughly considered and Hadamard's allowance for internal circulation is discussed, no mention is made of the limited range of internal circulation for which Bond and Newton postulated an interfacial tension factor. This is a very minor note of criticism since a good balance has been achieved between the various sections and the essential unity of the mass transfer and of this operation is well brought out.

These two volumes are outstanding in this field and present a formidable challenge to all previous chemical engineering text-books. F. H. GARNER

\section{Selecta Hermann Weyl}

(Herausgegeben zu seinem siebzigsten Geburtstag von der Eidgenössischen Technischen Hochschule in Zürich und vom Institute for Advanced Study in Princeton.) Pp. 592. (Basel und Stuttgart: Birk. häuser Verlag, 1956.) 48.90 francs ; 48.90 D.M.

$T$ HIS selection from the published papers of the late Hermann Weyl was prepared by a committee of his friends: Eckmann, Hopf and Plancherel in Zurich, and Morse, von Neumann and Selberg in Princeton. Their purpose was to choose from Weyl's works whatever was of permanent and historical importance, within the limits set by the size of a single volume. Weyl himself helped them with advice and approved their choice. He also added illuminating comments to some of the earlier papers, explaining how he came to write them and how his feelings about them changed in the light of later history. The volume was prepared for Weyl's seventieth birthday, and an advance copy was handed to him at the official celebration in Zurich. The public edition, appearing now after his death, will serve as an altogether fitting memorial to him.

Nineteen papers are reprinted, covering all Weyl's major interests in physics and mathematics. There is a bibliography of those which were left out. The well-known classical papers are all here. The reviewer started reading, not the famous papers, but those he had never heard of before. The same procedure is recommended to others. Every paper is then a surprise, filled with fresh insights and unexpected beauty.

\section{Tragic Safari}

By Albert Mahuzier. (Translated by Alec Brown.) Pp. $144+16$ plates. (London : Elek Books, Ltd., 1956.) 16s. net.

THIIS book is an account of a trip to French Equatorial Africa to make colour films of wild animals, especially at night by flashlight. All the plans went wrong, and the white hunter was mauled by a lion and bled to death for lack of proper 'first aid'. The author has unusual ideas about filming animals in the field : he apparently aims at getting his pictures after the white hunter has mortally wounded the victims, or after he has caught a leopard in a 'panther trap', an enormous gin anchored to a $\log$ of wood. Some of the illustrations of animals show living, tame, captives; the rest are portraits of corpses. The translation is poor and full of gallicisms; the translator has not bothered to find the English equivalents of many of the French names of animals so that the text speaks of the guib, bubale, cephalophus, potamocherus, and so on. The value of the book may be judged by the caption beneath a photograph of the body of a warthog; it informs the reader that the picture shows a "dead rhinoceros".

The blurb on the jacket says "It is Mahuzier himself who gives us 'the loveliest girl of Maripanda', her beater raised in one hand, while the fingers of the other caress the taut tom-tom skin to produce the intoxicating double-rhythm". Reference to the picture, however, shows "the belle of Maribanda" pounding mealies in a wooden mortar with her free hand on the edge to prevent the contents spilling as she reduces them to meal. Further comment is needless. $\quad$ L. Harrison Matthews

Advances in Catalysis and Related Subjects

Edited by W. G. Frankenburg, E. K. Rideal and V. I. Komarewsky. Vol. 7, 1955. Pp. $x i+362$. (New York: Academic Press, Inc.; London: Academic Books, Ltd., 1955.) 9 dollars; $72 s$.

THIS volume contains a series of monographs having as their general theme the nature of the chemical bonds formed between catalysts and adsorbed substrates, special attention being paid to electron-transfer processes involved in chemisorption on the surface of metals and semiconductors. Summaries are given of newer techniques for the study of chemisorption, including the use of the field emission microscope, by means of which it becomes possible to see images of individual molecules and to obtain valuable information on their constitution and configuration in the adsorbed state. In this way, a stage has been reached at which changes in state on adsorption can be followed by experimental observation.

Good reviews are also given of the theory of chemisorption and of modern high-vacuum working with clean surfaces. In the case of adsorption and catalysis on metals, it is perhaps a little unfortunate from the point of view of practical catalysis that this necessary provision of a clean adsorbing surface involves the use mainly of tungsten, which can easily be cleaned by high-temperature desorption but which 